\title{
Ileoanal pouches - Is mucosectomy essential?
}

\author{
ROGER R DOZOIS, MD, MS, FACS, EVA JUHASZ, MB, CHB
}

\begin{abstract}
RR DOZOIS, E JUHAsz. Ileoanal pouches - Is mucosectomy essential? Can J Gastroenterol 1993;7(2):258-262. Restorative ileal pouch-anal anastomosis (IPAA) with mucosectomy after proctocolectomy eradicates ulcerative proctocolitis, restores anorectal function, and avoids a permanent ileostomy. Its disadvantages include increased stooling frequency, imperfect continence especially at night, and pouchitis. Ileal pouch-distal rectal anastomosis (IPDRA) without mucosectomy promises to improve nighttime continence by preserving the mucosa of the anal transitional zone. Thus far, in controlled trials stool frequency and continence after IPDRA do not differ from that reported after IPAA with mucosectomy. It is unlikely that the risk of pouchitis will be diminished. However, the drawbacks of IPDRA relate to the residual diseased mucosa which may predispose patients to recurrent proctitis and associated symptoms, including persistent extracolonic manifestations, leading ultimately to poor functional results and increased risk of cancer. Therefore, IPAA with complete mucosectomy is preferable to IPDRA and continues to be the procedure of choice; it cures patients of the colitis, has broader indications, and appears to provide postoperative neorectal function comparable to that offered by IPDRA.
\end{abstract}

Key Words: Anal transitional zone, Ileal pouch-anal anastomosis, Mucosectomy

\section{Réservoir iléoanal - La résection de la muqueuse est-elle essentielle?}

RÉSUMÉ: Le réservoir iléal avec anastomose iléoanale et résection de la muqueuse, après une proctocolectomie élimine la proctocolite ulcéreuse, rétablit la fonction anorectale et évite l'iléostomie permanente. Parmi ses inconvénients, notons la fréquence accrue de la défécation, la continence imparfaite, particulièrement le soir, et l'inflammation de la muqueuse du réservoir. Le réservoir iléal avec anastomose iléorectale distale sans résection de la muqueuse permettrait une amélioration de la continence en préservant la muqueuse de la zone transitionnelle anale. Jusqu'à présent, dans des essais contrôlés, la fréquence de la défécation et la continence associées au réservoir iléal avec anastomose iléorectale distale ne different de celle que l'observe avec le réservoir iléal avec anastomose iléoanale et résection de la muqueuse. Il est peu probable que l'inflammation de la muqueuse de l'iléon soit différente. Les inconvénients du réservoir iléal avec anastomose iléorectale distale ont cependant trait aux résidus de muqueuse atteinte qui peuvent prédisposer les patients à la récidive de proctite et à ses symptômes, y compris les manifestations extra-coliques qui entraînent finalement un rendement fonctionnel faible et un risque accru de cancer. Donc, le réservoir iléal avec anastomose iléoanale et résection de la muqueuse est préférable à l'anastomose iléorectale distale et continue d'être l'intervention de choix; elle guérit le patient de sa colite, possède des indications plus vastes et semble offrir une fonction néorectale post-opératoire comparable à celle de l'anastomose iléorectale distale.

Section of Colon and Rectal Surgery, Mayo Clinic and Mayo Foundation, Rochester, Minnesota, USA

Correspondence and reprints: Dr Roger R Dozois, 200 First Street Southwest, Rochester, MN 55905, USA

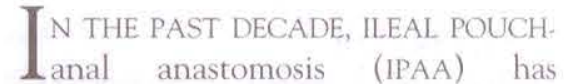
emerged as a successful therapeutic option in the surgical management of many patients with ulcerative colitis. The operation is attractive in that it excises all diseased bowel while it maintains transanal defecation and reasonable fecal continence. A most appealing feature, especially to patients, is the fact that the need for a permanent ileostomy is eliminated. Imperfect continence, especially at night, in some patients after IPAA has recently led some surgeons to explore the possibility that continence might be enhanced by avoiding mucosectomy, thus leaving intact the mucosa of the anal transitional zone, and stapling the ileal pouch to the distal rectal mucosa - ileal pouch-distal rectal anastomosis (IPDRA). With the hope of better defining how essential the anal 'mucosectomy' portion of the conventional IPAA is, this paper describes the technique of the two operations and discusses the advantages and disadvantages of each, including physiological and clinical results.

\section{ILEAL POUCH-ANAL ANASTOMOSIS WITH COMPLETE ANAL CANAL MUCOSECTOMY}

The operation: The major goal of the operation is eradication of disease, which implies complete removal of the diseased cecal, colonic, rectal and columnar anal canal mucosa, including the transitional zone area, while preserving anorectal function. The rectum is usually transected at the level of the levator ani and, after intraoperative confirmation of the diagnosis of ulcerative colitis by the surgi- 
cal pathologist, transanal mucosectomy is initiated. We favour doing the operation through a perineal approach, leaving a $3 \mathrm{~cm}$ rectal muscular cuff above the dentate line. The shorter cuff limits operative time, reduces the amount of bleeding and contamination, and favours fuller expansion of the neorectum (1). In addition, the likelihood of leaving behind residual mucosa is minimized (1). After exposing the dentate line area by dilating the anus with retractors, a dilute solution of adrenaline is injected submucosally to facilitate stripping of the mucosa from the underlying muscularis propria and to reduce bleeding (1). The endoluminal dissection with the electrocautery commences at the dentate line and extends circumferentially to the level of the levator ani, where the full thickness of the rectal wall is transsected, enabling en bloc removal of an intact tube of distal rectal and anal canal mucosa (1). After extensive mobilization of the mesentery to allow the apex of the future ileal reservoir to reach well beyond the inferior border of the pubic ramus, construction of the reservoir is begun. We have preferred a J-shaped ileal pouch similar to that used by Utsunomiya et al (2), stapling or sewing together two 15 to $20 \mathrm{~cm}$ limbs of terminal ileum (1). In the event that the J-shaped reservoir cannot easily reach the dentate line area, a handsewn S-shaped or W-shaped reservoir might be preferable. The IPAA is handsewn to mucosa at the dentate line using interrupted sutures of 3-0 vicryl. In most patients with ulcerative colitis, but less often in those with polyposis (3), a temporary diverting loop ileostomy is established.

Advantages and disadvantages: The major advantages of IPAA are that the diseased mucosa is entirely removed, transanal defecation is restored, and continence is well-preserved. The disadvantages include significant morbidity (4), the technically tedious mucosectomy, especially when the disease is severe, and the imperfect continence, especially at night, that may lead a certain number of patients to wear a protective pad (5).

Physiological studies: Numerous inter-

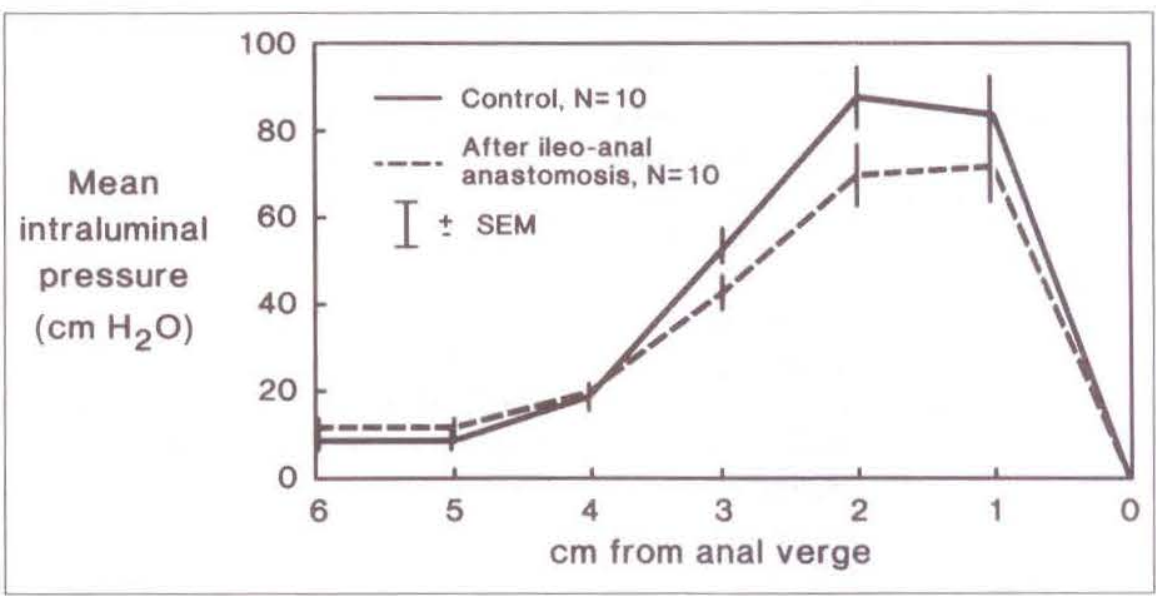

Figure 1) Mean and sphincter resting pressures in health and after ileoanal anastomosis. At each distance from anal verge, values in patients do not differ from controls $(P>0.05)$. (Reproduced with permission from Heppell J, et al. Ann Surg 1982;195:435-43)

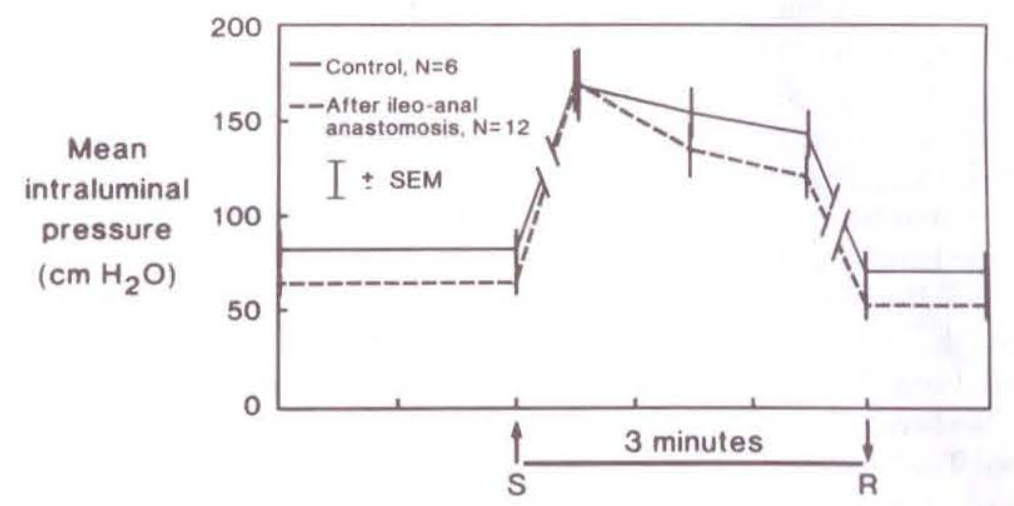

Figure 2) Mean response of anal sphincter pressure to squeeze in health and after ileoanal anastomosis. Control and postoperative values do not differ significantly ( $P>0.05)$. S Onset of squeeze; R Relaxation of squeeze. (Reproduced with permission from Heppell J, et al. Ann Surg $1982 ; 195: 435-43)$

acting anatomic and physiological factors are believed to be important in achieving continence. They include the anal sphincters, anorectal sensation, the puborectal and anorectal angle, the rectoanal inhibitory reflex, distensibility and capacity of the reservoir, pouch motility and ability to evacuate, the rapidity of transit through the more proximal bowel, and the quality and quantity of the enteric contents (4). This review focuses primarily on data pertaining to the anal transitional zone and the anal sphincter apparatus. After the ileoanal operation, the anal sphincter is unchanged in that the mean resting and squeeze pressures are generally maintained with only a small reduction compared with controls
(Figures 1,2) (6), but the rectoanal inhibitory reflex is undetectable. The decreases in anal resting pressure at night, especially during deepening sleep, are sometimes more profound in pelvic pouch patients than in healthy subjects, a situation that may be conducive to fecal soilage (7). The decrease in resting anal pressure observed has varied considerably between authors with some finding a lowering in the order of 40 to $50 \%(8,9)$. Johnston et al (8) reported that the mean resting pressure decreased from $85 \mathrm{~cm} \mathrm{H}_{2} \mathrm{O}$ before mucosectomy to $40 \mathrm{~cm} \mathrm{H}_{2} \mathrm{O}$ postoperatively. Similarly, Tuckson and colleagues (9) noted a diminution from 83 $\mathrm{mmHg}$ before mucosal stripping to 48 $\mathrm{mmHg}$ afterwards. Such changes in 
anal sphincter function after the operation have been attributed to operative damage to the sphincteric apparatus or its innervation and have been blamed on the surgical technique, the amount of time during which the anal sphincter is dilated, or the removal of the transitional zone mucosa. It is obvious, how. ever, that not all postoperative sphincteric changes and altered continence can be attributed to operative technique, as nighttime incontinence has been found to be much less in polyposis patients (3), in younger patients (5), in men (5), and in patients who have less diarrhea preoperatively (5). Moreover, nighttime continence, which is believed to depend largely on resting anal pressure, improves considerably with time (5). Finally, the quality and quantity of the enteric contents may play a crucial role, as nighttime incontinence has been observed in as many as 20 to $30 \%$ of patients whose entire rectum is left intact after ileorectostomy for familial polyposis (10-12). Clinical studies: In the authors' experience, the overall morbidity after IPAA has been $30 \%$ (4), with pelvic sepsis (5\%) being the most feared complication. The number of stools per 24 $h$ in IPAA patients tends to vary with the type of reservoir employed, but averages five to six stools (4). With time, the number of stools changes little, but the need for medications to augment transit time or stool consistency diminishes, and the ability of patients to discriminate between gas and stool improves (5). Moreover, daytime continence tends to be closer to normal than nighttime continence, but nighttime continence also improves dramatically with time and is superior in young men, patients with polyposis and those with less diarrhea preoperatively than in older women, colitis patients and those with more stools preoperatively (5). One would predict that the risk of adenocarcinoma developing after IPAA is nonexistent, but, to date, three patients have developed adenocarcinomas of the anorectal area after ileoanal anastomosis (13-15). In at least one patient, a long rectal mucosectomy had been performed (13), and in at least another one, severe dysplasia of the rec- tum was present at the time the mucosal proctectomy was performed (14). In the third report, neither the extent of the mucosectomy nor the presence or $a b$ sence of dysplasia at the time of operation are mentioned (15).

\section{ILEAL POUCH-DISTAL RECTAL ANASTOMOSIS WITHOUT MUCOSECTOMY}

The operation: The major goal of IPDRA is to improve continence by leaving intact 1 to $3 \mathrm{~cm}$ of anal canal and lower rectal mucosa above the dentate line, including the anal transitional mucosa. Thus, no mucosectomy is performed, and the ileal pouch can be either sewn or, as is most often done, stapled to the distal rectum or proximal anal canal at the pelvic floor $(8,16-18)$. The other aspects of the surgical techniques do not differ from those of the more conventional IPAA previously detailed, other than the choice of reservoir, which varies with authors.

Advantages and disadvantages: $\mathrm{Be}$ cause the operation avoids mucosectomy, it may be faster and safer than the conventional ileoanal anastomosis. Also, by leaving the transitional zone area intact, anal canal sensation and anal sphincter strength may be anticipated to be better preserved, thus, nighttime continence may be im. proved. The disadvantages are that it leaves the patient with a variable amount of diseased rectal and anal canal mucosa, which may in turn favour later recurrent flares of the disease with its associated, unwelcome symptoms, persistence of extracolonic manifestations and an increased risk of carcinoma.

Physiological studies: Tuckson and colleagues (9) found that patients who have a stapled procedure without mucosectomy have a higher mean maximal anal resting pressure $(64.6 \pm 5.3$ $\mathrm{mmHg}$ ) than do patients who had the endoanal manipulations associated with mucosectomy and a hand-sewn IPAA $(47.9 \pm 33 \mathrm{mmHg})$. Others have reported similar findings (19). Also, patients with retained transitional zone mucosa have sensory functions superior to those in whom the transitional mucosa has been stripped away $(20,21)$.
In one study, discrimination was not impaired by excision of the transition zone (20), while in another sensation was improved but resting pressure did not differ between the 'mucosectomy' and 'no mucosectomy' groups (21). In the St Mark's controlled, randomized trial, resting pressure also tended to decrease more in the mucosectomy/ hand-sewn group $\left(90 \mathrm{~cm} \mathrm{H}_{2} \mathrm{O}\right.$ before to $40 \mathrm{~cm} \mathrm{H}_{2} \mathrm{O}$ after operation) than in the no mucosectomy/stapled anastomosis group $\left(80 \mathrm{~cm} \mathrm{H}_{2} \mathrm{O}\right.$ before to $70 \mathrm{~cm} \mathrm{H}_{2} \mathrm{O}$ after operation) despite similar median duration of anal dilation (22). The threshold of anal sensation to electrical stimulation, however, was similar in both groups.

Of great importance is the finding that the retained mucosa is in all likelihood diseased. Indeed, histological examination of 50 colitis specimens removed by conventional proctocolectomy at the Mayo Clinic showed that ulcerative colitis was present in the transitional zone area within $1 \mathrm{~cm}$ of the dentate line in $90 \%$ of the specimens (23). Similarly, Sugarman and associates (19) observed that in most ulcerative colitis patients, the distal 'donut' of the rectum removed at the time of the stapled anastomosis harbored an inflamed mucosa. Finally, and of even greater concern, are reports that dysplasia and neoplasia can in fact be present or develop in this transitional zone mucosa in patients with ulcerative colitis $(24-26)$ or with familial polyposis $(24,26)$.

Clinical studies: Whether the stapled IPDRA is safer than IPAA is difficult to ascertain. Cohen and colleagues (27) reported a lesser risk of leak rate after stapled $(7 \%)$ compared with handsewn anastomosis $(12 \%)$. However, the latter group comprised their initial learning experience with the procedure. Despite this consideration, Cohen et al (27) found the sepsis rate was the same in stapled and hand-sewn technique groups ( $4 \%$ versus $3 \%$, respectively) (27). Also, avoiding a temporary ileostomy after stapled IPDRA increased the rate of sepsis to $10 \%(10)$, suggesting that these latter modifications in the performance of IPAA do not make the operation safer. 
Some authors have reported improved continence, especially at night, and the reduced need to wear a pad after IPDRA. These results, based primarily on retrospective uncontrolled studies $(18,19,28)$, have not thus far been corroborated by prospective, randomized clinical trials. Indeed, Nicholls and colleagues at St Mark's Hospital in London (22) found no difference in pelvic pouch function between IPAA and IPDRA in terms of continence, need to wear protective pads and need for medication (Table 1).

\section{DISCUSSION}

There is little doubt that the conventional IPAA or its latest modification (stapled anastomosis without prior mucosectomy) offers patents with ulcerative colitis a quality of life superior to that which might be anticipated after proctocolectomy and Brooke ileostomy or even the continent ileostomy of Koch $(29,30)$. Nonetheless, IPAA has four important limitations: high likelihood of immediate postoperative complications, frequent stools, imperfect continence especially at night, and the risk of pouchitis. Thus far, IPDRA does not appear to reduce immediate postoperative complications (27), and by leaving behind diseased mucosa it will most likely increase long term disability and complications. While various reservoir configurations may produce different stool frequencies, the number of stools per 24 $\mathrm{h}$ reported by many authors varies little and, in fact, resembles the number of times a Brooke ileostomy patient needs to empty his or her external appliance. Since the number of stools is unlikely to be affected by IPDRA, bleeding per rectum may become a more prominent and troublesome complaint of these patients. Such recurrent flares of the residual disease at the level of the anastomosis may lead to stenosis, fistula or abscess, not to mention exacerbation of extracolonic manifestations. Pouchitis, while it can be managed well in most instances with antibiotics, remains a distressing drawback of ileal reservoir construction and needs to be studied carefully. However, one would not ex-

\section{TABLE 1}

Neorectal function after hand-sewn and stapled ileoanal anastomosis

\begin{tabular}{lcc}
\hline Parameters & Hand-sewn $(n=14)$ & Stapled $(n=14)$ \\
\hline Months since ileostomy closure & 11 & 12 \\
Number of stools per $24 \mathrm{~h}$ & 4 & 4 \\
Continence & & 12 \\
Normal & 11 & 2 \\
Mucus leak & 3 & 0 \\
Fecal leak & 0 & 1 \\
Pad used & 2 & 2 \\
Antidiarrheal medication & 4 & 10 \\
Discrimination between gas and stool & 8 & \\
\hline
\end{tabular}

"Modified with permission from Seow-Choen, et al. Br J Surg 1991:78:430-4

pect that the risk of pouchitis will be lessened by IPDRA.

Whether IPDRA offers continence truly superior to IPAA remains debatable; thus far, this contention is not supported by prospective, randomized trials, at least over the short term. Only long term prospective, randomized clinical trials in a sufficient number of patients will provide the definitive answer to this question. Even in the event that IPDRA does offer a benefit, it would probably be marginal and would have to be weighed against numerous potential and real disadvantages. The disadvantages include the increased risk of recurrent flare of the residual disease and the possible increased risk of cancer, necessitating closer surveillance and repeated biopsies which are uncomfortable for the patient and increase the cost of care. With either procedure, the risk of cancer will admittedly be small, although logically it should be dependent on the amount of diseased mucosa retained. Another drawback of IPDRA compared with IPAA is that it should not be offered to patients with severe rectal disease extending to the dentate line, those with associated dysplasia and/or cancer elsewhere in the colon, and those with extracolonic manifestations which are more likely to persist if diseased mucosa is left behind.

In conclusion, the 'conventional' IPAA with complete mucosectomy is preferable and remains our procedure of choice; indeed, it 'cures' patients of the colitis, has broader indications and appears to provide postoperative neorectal function not dissimilar to that offered by IPDRA.

\section{REFERENCES}

1. Dozois RR. Technique of ileal pouch-anal anastomosis. Perspect Colon Rectal Surg 1989;2:85-94.

2. Utsunomiya J, Iwama $T$, Imajo $H$, et al. Total colectomy, mucosal proctectomy, and ileoanal anastomosis. Dis Colon Rectum 1980;23:459-66.

3. Dozois RR, Kelly KA, Welling DR, et al. Ileal pouch-anal anastomosis: Comparison of results in familial adenomatous polyposis and chronic ulcerative colitis. Ann Surg 1989;210:268-73.

4. Kelly KA, Pemberton JH, Wolff BG, Dozois RR. Ileal pouch-anal anastomosis. Curr Probl Surg 1992;29:65-131.

5. Pemberton JH, Kelly KA, Beart RW Jr, Dozois RR, Wolff BG, Ilstrup DM. Ileal pouch-anal anastomosis for chronic ulcerative colitis: Long-term results. Ann Surg 1987;206:504-13.

6. Heppell J, Kelly KA, Phillips SF, Beart RW Jr, Telander RL, Peffault J. Physiologic aspects of continence after colectomy, mucosal proctectomy, and endorectal ileo-anal an astomosis. Ann Surg 1982;195:435-43.

7. Orkin BA, Soper NJ, Kelly KA, Dent J. Influence of sleep on anal sphincteric pressure in health and after ileal pouch-anal anastomosis. Dis Colon Rectum 1992;35:137-44.

8. Johnston D, Holdsworth PJ, Naysmyth DG, Neal DE, Primrose JN, Womack N, et al. Preservation of the entire anal canal in conservative proctocolectomy for ulcerative colitis: A pilot study comparing end-to-end ileo-anal anastomosis without mucosal resection with mucosal proctectomy and endo-anal anastomosis. Br J Surg 1987;74:940-4.

9. Tuckson W, Lavery I, Fazio V, Oakley J, Church J, Milsom J. Manometric and functional comparison of ileal pouch anal anastomosis with and without anal manipulation. Am J Surg 1991;161:90-6. 
10. Newton CR, Baker WNW. Comparison of bowel function after ileorectal anastomosis for ulcerative colitis and colonic polyposis. Gut 1975; 16:785-91.

11. Ambroze WL, Dozois RR, Pemberton JH, Beart RW Jr, Ilstrup DM. Familial adenomatous polyposis: Results following ileal pouch-anal anastomosis and ileorectostomy. Dis Colon Rectum 1992;35:12-5.

12. Madden MV, Neale KF, Nicholls RJ, et al. Comparison of morbidity and function after colectomy with ileorectal anastomosis or restorative proctocolectomy for familial adenomatous polyposis. Br J Surg 1991;78:789-92.

13. Ravitch MM. Presidential address: The reception of new operations. Ann Surg 1984;200:231-46.

14. Stem H, Walfisch S, Mullen B, McLeod R, Cohen Z. Cancer in an ileoanal reservoir: $A$ new late complication? Gut 1990;31:473-5.

15. Puthu D, Rajan N, Rao R, Rao L, Venugopal P. Carcinoma of the rectal pouch following restorative proctocolectomy: Report of a case. Dis Colon Rectum 1992;35:257-60.

16. Peck DA. Stapled ileal reservoir to anal anastomosis. Surg Gynecol Obstet 1988;166:562-4.

17. Kmiot WA, Keighley MRB. Totally stapled abdominal restorative proctocolectomy. Br J Surg 1989;76:961-4.
18. Martin LW, Torres AM, Fischer JE, Alexander $F$. The critical level for preservation of continence in the ileoanal anastomosis. J Ped Surg 1985;20:664-7.

19. Sugarman HJ, Newsome HF, DeCosta G, Zfass AM. Stapled ileoanal anastomosis for ulcerative colitis and familial polyposis without a temporary diverting ileostomy. Ann Surg 1991;213:606-19.

20. Keighley MRB, Winslet MC, Yoshioka $\mathrm{K}$, Lightwood R. Discrimination is not impaired by excision of the anal transition zone after restorative proctocolectomy. $\mathrm{Br}$ J Surg 1987;74:1118-21.

21. Miller R, Bartolo DCC, Orrom WJ, Mortensen NJM, Roe AM, Cervero F. Improvement of anal sensation with preservation of the anal transition zone after ileoanal anastomosis for ulcerative colitis. Dis Colon Rectum 1990;33:414-8.

22. Seow-Choen, Tsunoda A, Nicholls RJ Prospective randomized trial comparing anal function after hand sewn ileoanal anastomosis with mucosectomy versus stapled ileoanal anastomosis without mucosectomy in restorative proctocolectomy. Br J Surg 1991;78:430-4.

23. Ambroze WL, Pemberton JH, Dozois RR, Carpenter HA, O'Rourke JS, Ilstrup DM. The histologic pattern and pathologic involvement of the anal transition zone in patients with ulcerative colitis. Gastroenterology. (In press)

24. Tsunoda A, Talbot IC, Nicholls RJ. Incidence of dysplasia in the anorectal mucosa in patents having proctocolectomy. Br J Surg 1990;77:506-8.

25. King DW, Lubowski DZ, Cook TA. Anal mucosa in restorative proctocolectomy for ulcerative colitis. Br J Surg 1989;76:970-2.

26. Emblem R, Bergan A, Larsen S. Straight ileoanal anastomosis with preserved anal mucosa for ulcerative colitis and familial polyposis. Scand J Gastroenterol 1988;23:913-9.

27. Cohen Z, McLeod R, Stem H, Reznick R. Continuing evaluation of the pelvic pouch procedure. Ann Surg. (In press)

28. Lavery IC, Tuckson WB, Fazio VW, et al. Pouch surgery: The importance of the transitional zone. Can J Gastroenterol 1990;4:428-31.

29. Pemberton JH, Phillips SF, Ready RR, Zinsmeister AR, Beahrs OH. Quality of life after Brooke ileostomy and ileal pouch-anal anastomosis: Comparison of performance status. Ann Surg 1989;209:620-8.

30. Kohler LW, Pemberton IH, Zinsmeister AR, Kelly KA. Quality of life after proctocolectomy: A comparison of Brooke ileostomy, Koch pouch, and ileal pouch-anal anastomosis. Gastroenterology 1991;101:679-84. 


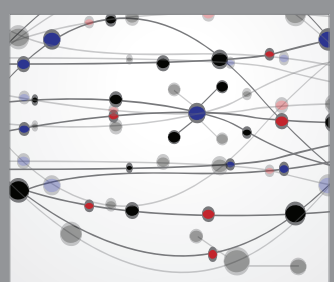

The Scientific World Journal
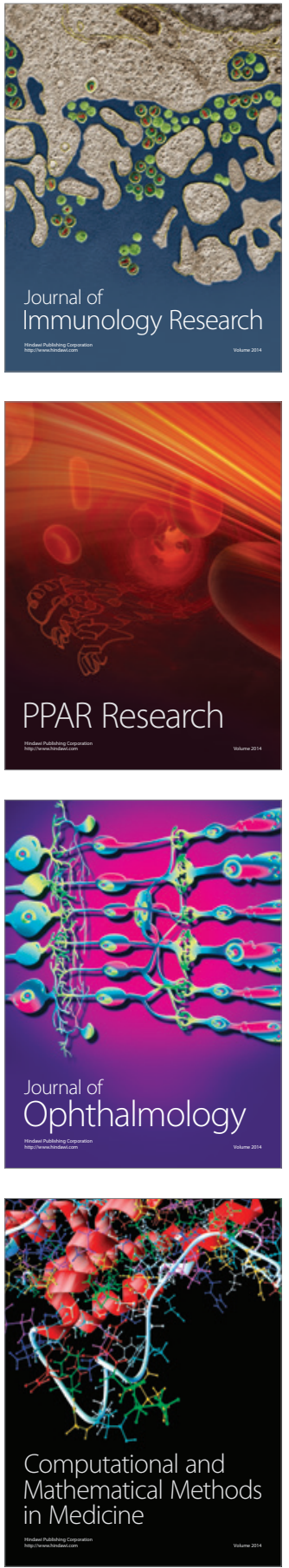

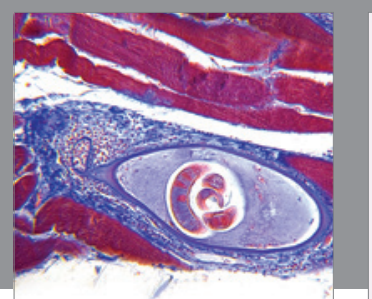

Gastroenterology Research and Practice

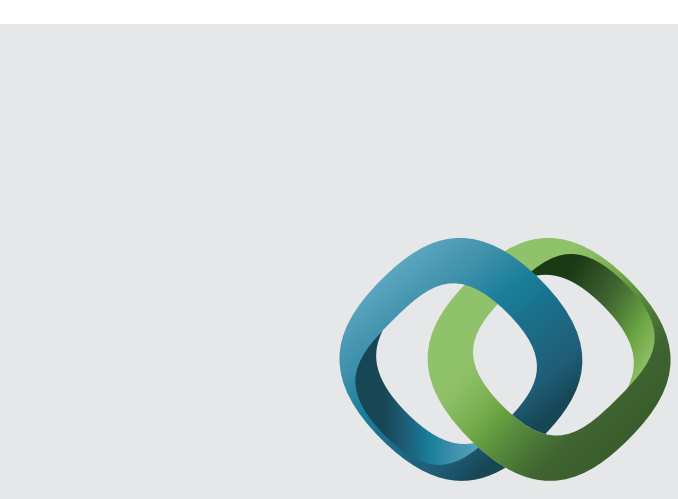

\section{Hindawi}

Submit your manuscripts at

http://www.hindawi.com
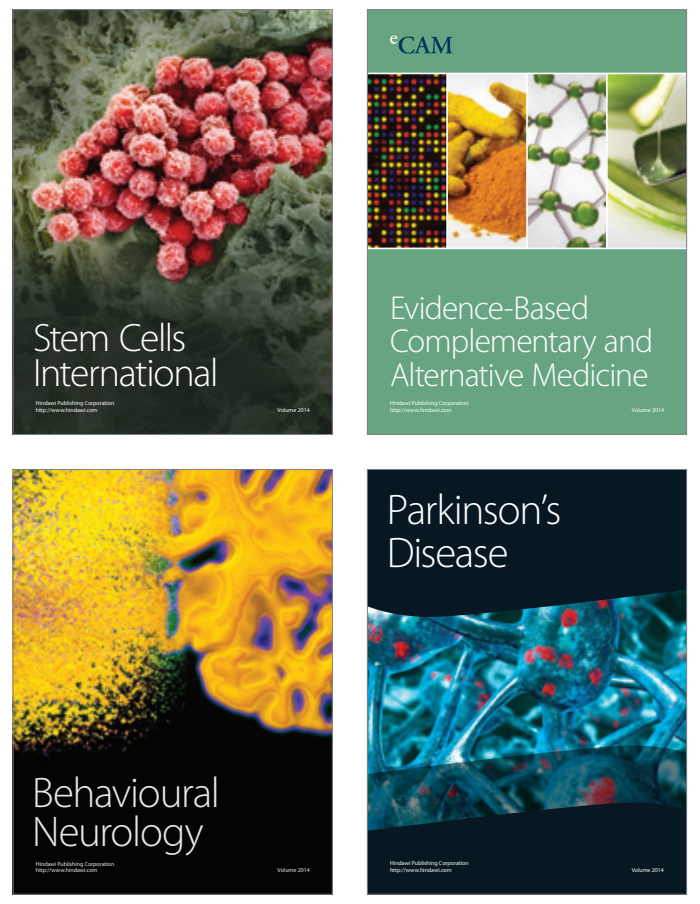
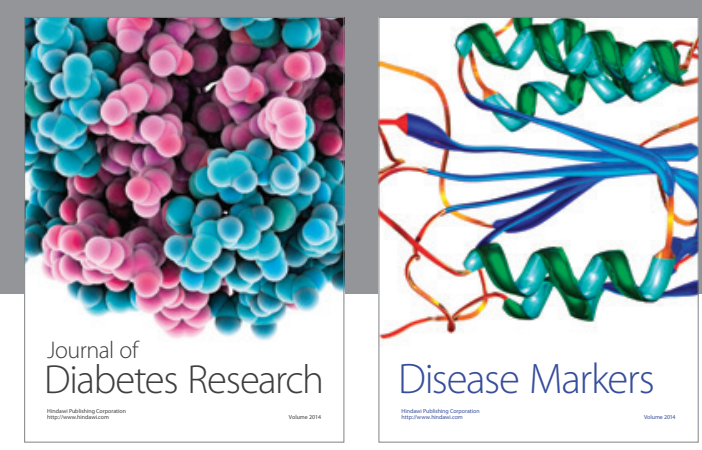

Disease Markers
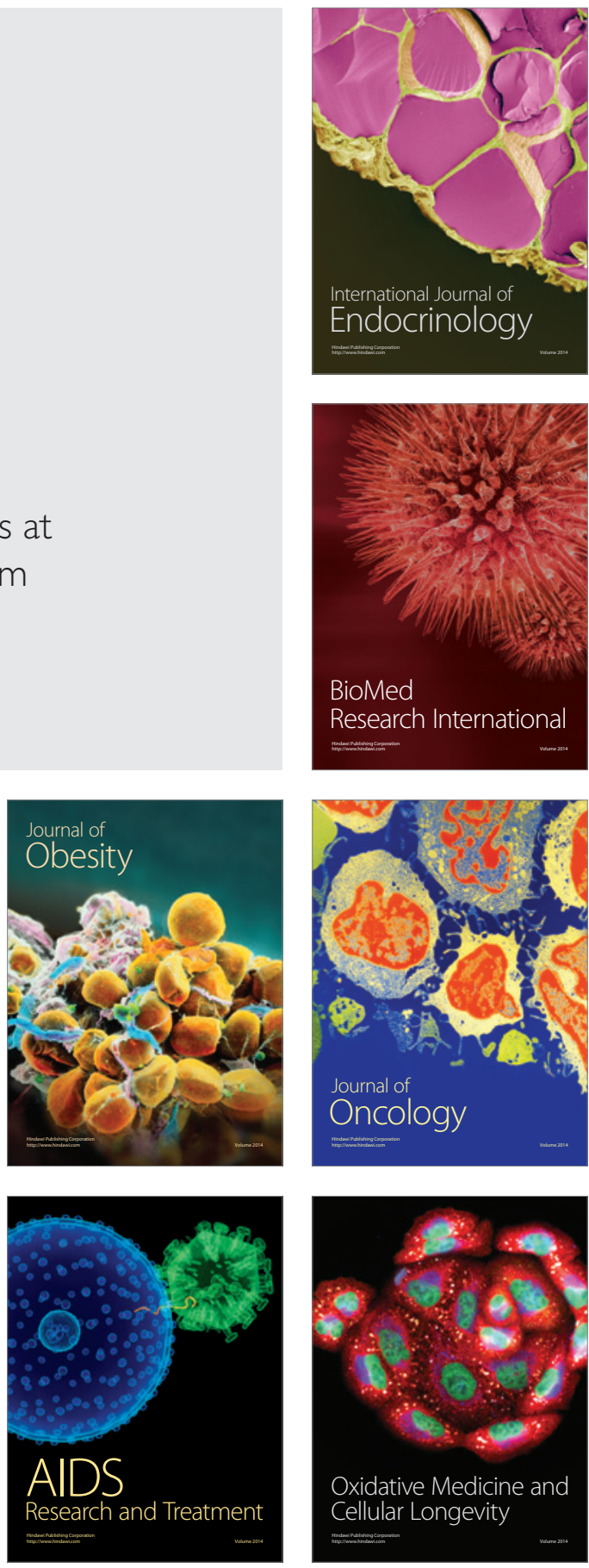